\title{
Communication concepts vs. Sciences concepts
}

\author{
Daniela Giffu ${ }^{1}$, Mirela Teodorescu ${ }^{2, *}$ \\ 1“Alexandru loan Cuza” University of Iaşi, Bd. Carol I no. 11, 700506, Romania \\ ${ }^{2}$ University of Craiova, 13 A. I. Cuza Street, Craiova, 200585, Romania \\ *E-mail address: mirteodorescu@yahoo.com
}

\begin{abstract}
The scientists as Bateson, Watzlawick expresses the determining role of interaction in the axiom of the "impossibility of not communicating". All behavior (verbal and nonverbal) occurring between persons who are conscious of each other's presence has behavioural effects, whether intended or not. Such effects have interpersonal message value, and thus are communicative in nature. Since it is impossible for humans not to behave in one way or another, it follows that in interaction it is impossible not to communicate (Bateson, 1963; Watzlawick et al., 1967). Communication theory is relatively new as science and interacts with the other disciplines of sciences. During its development some of the notions were used that were already committed and comprehensive. This article aims to present some of them. Terms as system, input, output, feedback, entropy specific to scientific disciplines as systems theory, cybernetics, information theory, physics, are especially used in communication theory.
\end{abstract}

Keywords: systems theory; entropy; centripetal force; centrifugal force; communication theory

\section{CENTRIFUGAL AND CENTRIPETAL FORCES}

Centrifugal force (from Latin centrum, meaning "center", and fugere, meaning "to flee" (Craig, 1849), is the apparent force that draws a rotating body away from the center of rotation. It is caused by the inertia of the body as the body's path is continually redirected. In Newtonian mechanics, the term centrifugal force is used to refer to one of two distinct concepts: an inertial force (also called a centripetal force).

Newton described the role of centrifugal force upon the height of the oceans near the equator in the Principia: "Since the centrifugal force of the parts of the earth, arising from the earth's diurnal motion, which is to the force of gravity as 1 to 289 , raises the waters under the equator to a height exceeding that under the poles by 85472 Paris feet, as above, in Prop. XIX., the force of the sun, which we have now showed to be to the force of gravity as 1 to 12868200 , and therefore is to that centrifugal force as 289 to 12868200 , or as 1 to 44527 , will be able to raise the waters in the places directly under and directly opposed to the sun to a height exceeding that in the places which are 90 degrees removed from the sun only by one Paris foot and $113 \mathrm{~V}$ inches; for this measure is to the measure of 85472 feet as 1 to 44527 " ( Newton, 2010). 
Centrifugal force has also played a role in debates in classical mechanics about detection of absolute motion. Newton suggested two arguments to answer the question of whether absolute rotation can be detected: the rotating bucket argument, and the rotating spheres argument (Newton, 1934). According to Newton, in each scenario the centrifugal force would be observed in the object's local frame (the frame where the object is stationary) only if the frame were rotating with respect to absolute space. The analogy between centrifugal force (sometimes used to create artificial gravity) and gravitational forces led to the equivalence principle of general relativity (Barbour \& Herbert Pfister, 1995; Eriksson, 2008).

Centrifugal forces means forces that disrupt internal order and further the destruction of a country: ethnic conflicts; competing claims among ethnic groups, religion, poorly run government and/or transportation systems; a dissident minority seeking autonomy; devolution: transfer of power from the state's central government to separate political subdivisions within its territory.

Centripetal force (from Latin centrum "center" and petere "to seek", (Craig John, 1849), is a force that makes a body follow a curved path: its direction is always orthogonal to the velocity of the body, toward the fixed point of the instantaneous center of curvature of the path. Centripetal force is generally the cause of circular motion.

In simple terms, centripetal force is defined as a force which keeps a body moving with a uniform speed along a circular path and is directed along the radius towards the centre (Russelkl C Hibbeler, 2009; Paul Allen Tipler \& Gene Mosca, 2003). The mathematical description was derived in 1659 by Dutch physicist Christiaan Huygens (Germain \& Caillerie, 2012). Isaac Newton's description was: "A centripetal force is that by which bodies are drawn or impelled, or in any way tend, towards a point as to a centre" (Newton, 2010).

The centripetal force acts from the center of mass of the rotating object, on an object a distance " $\mathrm{r}$ " from its center. If both objects are rotating they will affect each other; for circular orbits, the center of mass is the center of the circular orbits. For non-circular orbits or trajectories, only the component of force directed orthogonally to the path (toward the center of the osculating circle) is termed centripetal; the remaining component acts to speed up or slow down the satellite in its orbit (Johnnie T. Dennis, 2003). For an object swinging around on the end of a rope in a horizontal plane, the centripetal force on the object is supplied by the tension of the rope. For a spinning object, internal tensile stress provides the centripetal forces that make the parts of the object trace out circular motions.

For humanistic sciences, centripetal forces mean forces or attitude that promote national unity and solidarity. The ultimate centripetal force is the nation's "raison d'etre" as: reason for being, every state must have a reason to exist: defending a culture or ideology, standing up to a common enemy, special status in the world; states that don't have a raison d'etre try to create one to unify the people (Baxter, 1988).

Examples of centripetal forces:

1. Nationalism is the primary source of group identity in the modern state: it is the idea that a person derives a significant part of his identity from a sense of belonging to a nation; states try to create allegiance to keep country stable: want their populace to accept the ideology, adhere to laws, participate in its operation; icons - flags, national sports teams, holidays (Rawlins, 1988).

2. Unifying institutions: schools, the armed forces and state churches, religion can be a unifying, cohesive force, like Buddhism in Thailand, Judaism in Israel.

3. Organization and administration of the government. 
4. Transportation and communication.

5. A perceived threat to a group's sense of identity.

The humanity foundation relies on solidarity. The power of social cohesion comes from the primary tendency of attachment and trust. It is inevitable to become human without passing through the corridor of the communion selection. The engine of social consistency is the influence. Related to this system of social reproduction, two inertias are defined. The centrifugal inertia of the social system is called alienation (Vlăduţescu, 2006). This type of social connection covers the phenomenon of remaining outside the circuits of the social influence. The alienation is a frail force. The alienation network is weak and with no consolidation mechanisms. Thus the alienation appears as a system error, as a grip of the social influence gear. The centripetal inertia focuses on the concept of power. The power operators are those who know and can place themselves at the commanding nodes of the social influence. Any kind of power is an influencing power. We learn to discover ourselves, to explore ourselves, to get close to the others, to understand and understand each other in terms of influences, in the parameters of some grids of influence (Vladutescu, 2006).

\section{ENTROPY}

The concept of entropy was introduced by Rudolf Clausius in 1865 . He was the first to enunciate the second law of thermodynamics by saying that "entropy always increases" (Clausius Rudolf, 1850). In thermodynamics, entropy (usual symbol $S$ ) is a measure of the number of specific ways in which a thermodynamic system may be arranged, often taken to be a measure of disorder, or a measure of progressing towards thermodynamic equilibrium. The entropy of an isolated system never decreases, because isolated systems spontaneously evolve towards thermodynamic equilibrium, the maximum entropy. Systems which are not isolated may decrease in entropy (Vlăduţescu, 2010; Vlăduţescu \& Ciupercă, 2013)). Since entropy is a state function, the change in the entropy of a system is the same for any process going from a given initial state to a given final state, whether the process is reversible or irreversible. However irreversible processes increase the combined entropy of the system and its environment (Brooks \& Wiley, 1988).

"The logarithmic connection between entropy and probability was first stated by L. Boltzmann in his kinetic theory of gases" (Planck, 1896). This is the famous formula for entropy $S$ (Clausius, 1850; Shannon, 1948).

$$
\mathrm{S}=\mathrm{k}_{\mathrm{B}} \ln \mathrm{W}
$$

where $k_{B}$ is Boltzmann's constant, and $\ln$ is the natural logarithm, $W$ is the frequency of occurrence of a macrostate or, more precisely, the number of possible microstates corresponding to the macroscopic state of a system - number of (unobservable) "ways" in the (observable) thermodynamic state of a system can be realized by assigning different positions and momentum to the various molecules (Vladutescu, 2002).

Entropy has often been loosely associated with the amount of order, disorder, and/or chaos in a thermodynamic system. The traditional qualitative description of entropy is that it refers to changes in the status quo of the system and is a measure of "molecular disorder" and the amount of wasted energy in a dynamical energy transformation from one state or form to another. In this direction, several recent authors have derived exact entropy formulas to account for and measure disorder and order in atomic and molecular assemblies (Brooks, Daniel, Wiley, 1988; Landsberg, P.T., 1984a; Landsberg, P.T. 1984b). One of the simpler 
entropy order/disorder formulas is that derived in 1984 by thermodynamic physicist Peter Landsberg, based on a combination of thermodynamics and information theory arguments. He argues that when constraints operate on a system, such that it is prevented from entering one or more of its possible or permitted states, as contrasted with its forbidden states, the measure of the total amount of "disorder" in the system is given by (Landsberg, 1984a, Landsberg, 1984b):

$$
\text { Disorder }=\mathrm{C}_{\mathrm{D}} / \mathrm{C}_{\mathrm{I}}
$$

Similarly, the total amount of "order" in the system is given by:

$$
\text { Order }=1-\mathrm{C}_{\mathrm{O}} / \mathrm{C}_{\mathrm{I}}
$$

In which $C_{D}$ is the "disorder" capacity of the system, which is the entropy of the parts contained in the permitted ensemble, $C_{I}$ is the "information" capacity of the system, an expression similar to Shannon's channel capacity, and $C_{O}$ is the "order" capacity of the system (Brooks \& Wiley, 1988).

In information theory, entropy is the measure of the amount of information that is missing before reception and is sometimes referred to as Shannon entropy (Tribus, McIrvine, 1971; Balian, 2004), Shannon entropy is a broad and general concept which finds applications in information theory as well as thermodynamics. It was originally devised by Claude Shannon in 1948 to study the amount of information in a transmitted message. The definition of the information entropy is, however, quite general, and is expressed in terms of a discrete set of probabilities (Vlăduţescu, 2002). In the case of transmitted messages, these probabilities were the probabilities that a particular message was actually transmitted, and the entropy of the message system was a measure of the average amount of information in a message. For the case of equal probabilities (i.e. each message is equally probable), the Shannon entropy (in bits) is just the number of yes/no questions needed to determine the content of the message (Frigg \& Werndl, 2010; Vlăduţescu, 2013).

\section{SYSTEMS THEORY, CONTROL SYSTEMS, COMMUNICATION THEORY}

Hegel developed in the $19^{\text {th }}$ century a theory to explain historical development as a dynamic process. Marx and Darwin used this theory in their work. System theory was used by L. von Bertalanffy, a biologist, as the basis for the field of study known as 'general system theory', a multidisciplinary field (1968). Some influences from the contingency approach can be found in system theory (Bateson, 1979).

Basically Assumptions

System theory is the trans disciplinary study of the abstract organization of phenomena, independent of their substance, type, or spatial or temporal scale of existence. It investigates both the principles common to all complex entities, and the (usually mathematical) models which can be used to describe them. A system can be said to consist of four things (Parsons, 1977; Bertalanffy, 1962): 1. objects - the parts, elements, or variables within the system, these may be physical or abstract or both, depending on the nature of the system; 2.a system consists of attributes - the qualities or properties of the system and its objects; 3 . a system had internal relationships among its objects; 4 . systems exist in an environment. 
"Systems theory is frequently identified with cybernetics and control theory" (Bertalanffy, 1962).The fundamental systems-interactive paradigm of organizational analysis features the continual stages of input, throughput (processing), and output, which demonstrate the concept of openness/closeness (Belea, 1983; Bertalanffy, 1962). A closed system does not interact with its environment. It does not take in information and therefore is likely to atrophy, that is to vanish. An open system receives information, which it uses to interact dynamically with its environment. Openness increases its likelihood to survive and prosper. Several system characteristics are: wholeness and interdependence (the whole is more than the sum of all parts), correlations, perceiving causes, chain of influence, hierarchy, suprasystems and subsystems, self-regulation and control, goal-oriented, interchange with the environment, inputs/outputs, the need for balance/homeostasis, change and adaptability (morphogenesis) and equifinality: there are various ways to achieve goals (Stichweh, 2000; Calin \& Belea, 1973).

Topics in control theory are stability, Controllability and Observability. The systems are classified as linear systems control, nonlinear systems control, decentralized systems. Every control system must guarantee first the stability of the closed-loop behavior. For linear systems, this can be obtained by directly placing the poles. Non-linear control systems use specific theories (normally based on Aleksandr Lyapunov's Theory) to ensure stability without regard to the inner dynamics of the system (Belea, 1983). Adaptive control uses online identification of the process parameters, or modification of controller gains, thereby obtaining strong robustness properties (Belea, 1983). A hierarchical control system is a type of control system in which a set of devices and governing software is arranged in a hierarchical tree. When the links in the tree are implemented by a computer network, then that hierarchical control system is also a form of Networked control system. Intelligent control uses various AI computing approaches like neural networks, Bayesian probability, fuzzy logic (Liu, Jie, Wang, Golnaraghi, Kubica, 2010), machine learning, evolutionary computation and genetic algorithms to control a dynamic system.

It is accepted that "any process corresponds to a system" (M. Carpov, 1978). The role of communication is to ensure the performing of the communication process. Elements modify, within certain limits, the valences to promote cardinal function of the system. They perform, in their role of moment, a range of related behaviours, interactive, and while different parts that compose a set that defines the item as part of the communication system and a piece of the gear device that performs the process. On the other hand, each element (factor) of the process has, in its turn, systemic character: the code is a system of signs (language, formal language, etc..), communicator (producer) and receiver (consumer) are biopsycho-social systems, the channel forms a system, etc. (Vlăduţescu, 2014).

Communication has a certain dynamic, both in the system and structure of the process. It represents individuals as unitary personalities whose essence consists of the system of relations that they are involved in in the individual qualities and characteristics. Individual enters in the communication process by whole its bio-psycho-social structures: with his circle of relationships, its motivations, skills, attitudes and character, his temperament, his body and psyche. Both aspects of communication, social and individual (personal) are involved in the interaction with the environment. Communication is an interaction, a field of tensions, centrifugal and centripetal forces. They appear and act in the dialectical relationship between what interlocutors aspire to maintain intact by forces, inertia (relations role, status, dominance-submissiveness etc.) and which aim to influence change by force, persuasion, compliance, authority and so on (Dima \& Vlăduţescu, 2012).

The Interactional View requires a network of communication rules that govern a family homeostasis, which is the tacit collusion of family members to maintain the status quo. Even if the status quo is negative it can still be hard to change. Interactional theorists believe that 
we will fail to recognize this destructive resistance to change unless we understand Watzlawick's axioms. The following axioms can explain how miscommunication can occur if all the communicators are not on the same page. If one of these axioms is somehow disturbed, communication might fail. All of these axioms are derived from the work of Gregory Bateson, much of which is collected in Steps to an Ecology of Mind (1972).

Watzlawick, Bavelas, and Jackson support these axioms to maintain family homeostasis.

- One Cannot Not Communicate

- Every communication has a content and relationship aspect such that the latter classifies the former and is therefore a metacommunication. Metacommunication is communication about communication. Relationship messages are always the most important element in communication.

- The nature of a relationship is dependent on the punctuation of the partners communication procedures:

- Human communication involves both digital and analog modalities: This axiom refers back to the use of non-verbal and system strategy explained in the first axiom. It is mostly related to the digital content of communication within a relationship.

- Inter-human communication procedures are either symmetric or complementary:

- Communication is a continuous and irreversible process;

- Communication supposes adjusting and regulation.

\section{FEEDBACK}

Feedback is a process in which information about the past or the present influences the same phenomenon in the present or future. As part of a chain of cause-and-effect that forms a circuit or loop, the event is said to "feedback" into itself (Herold \& Greller, 1977). Feedback is commonly divided into two types - usually termed positive and negative. The terms can be applied in two contexts:

1. the altering of the gap between reference and actual values of a parameter, based on whether the gap is widening (positive) or narrowing (negative), ( Ramaprasad.1982);

2. the valence of the action or effect that alters the gap, based on whether it has a happy (positive) or unhappy (negative) emotional connotation to the recipient or observer (Herold, David M., and Martin M. Greller, 1977).

A feedback loop to control human behaviour involves four distinct stages (Goetz, 2011)

1. Evidence. A behaviour must be measured, captured, and data stored.

2. Relevance. The information must be relayed to the individual, not in the raw-data form in it was captured in, but in a context that makes it emotionally resonant.

3. Consequence. The information must illuminate one or more paths ahead.

4. Action. There must be a clear moment when the individual can recalibrate a behavior, make a choice, and act. Then that action is measured, and the feedback loop can run once more, every action stimulating new behaviors that inch the individual closer to their goals. 


\section{CONCLUSION}

The origins of communication theory is linked to the development of information theory in the early 1920s. Limited information-theoretic ideas had been developed at Bell Labs, all implicitly assuming events of equal probability. "The fundamental problem of communication is that of reproducing at one point either exactly or approximately a message selected at another point" (Shannon, 1948). In 1999 Craig wrote a landmark article "Communication Theory as a Field" which expanded the conversation regarding disciplinary identity in the field of communication, "(...) Although there exist many theories of communication (...) there is no consensus on communication theory as a field" (Craig, 1999).

\section{ACKNOWLEDGMENT}

This work was partially supported by the grant number 33C/2014, awarded in the internal grant competition of the University of Craiova.

\section{References}

[1] Julian B. Barbour, Herbert Pfister (1995). Mach's principle: from Newton's bucket to quantum gravity. Birkhäuser.

[2] Andrzej Borowski, International Letters of Social and Humanistic Sciences 14 (2014) 7-17.

[3] Ştefan Vlăduţescu, European Scientific Journal 9(32) (2013).

[4] Jason L. Powell, International Letters of Social and Humanistic Sciences 7 (2014) 22-30.

[5] C. Belea (1983). Teoria Sistemelor. Bucureşti: Editura Tehnica.

[6] Roger Balian (2004). Entropy, a Protean concept. In Jean Dalibard, Poincaré Seminar 2003: Bose-Einstein condensation - entropy. Basel: Birkhäuser.

[7] Andrzej Borowski, International Letters of Social and Humanistic Sciences 11 (2014) $1-168$.

[8] Ş. Vlăduțescu, E. M. Ciupercă (2013). Next Flood Level of Communication: Social Networks. Aachen: Shaker Verlag.

[9] Daniel R. Brooks, E. O. Wiley (1988). Evolution as Entropy - Towards a Unified Theory of Biology. University of Chicago Press.

[10] Andrzej Borowski, International Letters of Social and Humanistic Sciences 3 (2013) 69-74.

[11] Ștefan Vlăduțescu, International Letters of Social and Humanistic Sciences 15 (2014) 164-170.

[12] Sergiu Calin, Constantin Belea (1973). Sisteme automate complexe. Editura Tehnica.

[13] Robert T. Craig (1999). Communication Theory as a Field. International Communication Association. Retrieved. 
[14] John Craig (1849). A new universal etymological, technological and pronouncing dictionary of the English language: embracing all terms used in art, science, and literature. Volume 1. Harvard University.

[15] M. Siminică, A. Traistaru, International Journal of Education and Research 1(12) 2013.

[16] Ştefan Vlăduţescu (2013). What Kind of Communication Is Philosophy. Jokull.

[17] Ingrid V. Eriksson (2008). Science education in the 21st century. Nova Books.

[21] R. Frigg, C. Werndl (2010). Entropy - A Guide for the Perplexed. Oxford University Press, Oxford.

[22] Thomas Goetz, Wired Magazine (Wired Magazine). Retrieved (2011).

[23] Andrzej Borowski, International Letters of Social and Humanistic Sciences 4 (2013) 70-74.

[24] Ștefan Vlăduțescu (2013). Principle of the Irrepressible Emergence of the Message. Jokull.

[25] B. M. Dascălu (2014). Echivocul imagologic în Caietele lui Emil Cioran. Studii de Ştiinţă şi Cultură.

[26] Russelkl C. Hibbeler (2009), Equations of Motion: Normal and tangential coordinates. Engineering Mechanics: Dynamics (12 ed.). Prentice Hall.

[27] Ioan Constantin Dima, Ştefan Vlăduţescu (2012). Persuasion elements used in logistical negotiation: Persuasive logistical negotiation. Saarbrucken: LAP Lambert Academic Publishing.

[28] David M. Herold, Martin M. Greller, Academy of management Journal 20(1) (1977).

[29] Andrzej Borowski, International Letters of Social and Humanistic Sciences 6 (2013) $86-90$.

[30] Ştefan Vlăduţescu, International Letters of Social and Humanistic Sciences 10(2) (2014) 100-106.

[31] P. T. Landsberg, J. Stat. Physics 35(1984).

[32] M. Colhon (2013). Automatic Lexical Alignment between Syntactically Weak Related Languages. Application for English and Romanian. In Computational Collective Intelligence. Technologies and Applications (pp. 266-275). Springer Berlin Heidelberg.

[33] Jie Liu, Golnaraghi Kubica Wang, Fuzzy Sets and Systems (2010).

[36] Isaac Newton,(2010). The principia : mathematical principles of natural philosophy. Snowball Pub.

[37] Andrzej Borowski, International Letters of Social and Humanistic Sciences 4 (2013) 70-74.

[38] Ştefan Vlăduţescu, International Journal of Education and Research 1(11) (2013).

[39] F. Hristea, M. Colhon (2012). Feeding syntactic versus semantic knowledge to a knowledge-lean unsupervised word sense disambiguation algorithm with an underlying Nä̈ve Bayes model. Fundamenta Informaticae.

[40] Claude Elwood Shannon, The Bell System Technical Journal (1948). 
[42] William K. Rawlins (1988). A Dialectical Analysis of the Tensions, Functions and Strategic Challenges of Communication in Young Adult Friendships. Communication Yearbook. Newbury, CA: Sage.

[44] Ştefan Vlăduţescu (2002). Informaţia de la teorie către ştiinţă. Bucureşti: Editura Didactică şi Pedagogică.

[45] Ştefan Vlăduţescu, American International Journal of Contemporary Research 3(10) (2013).

[46] M. Tribus, E. C. McIrvine, Scientific American 224 (1971).

[48] Paul Allen Tipler Gene Mosca (2003). Physics for scientists and engineers (5th ed.). Macmillan.

[49] P. Germain, M. Piau, D. Caillerie, ed. (2012). Theoretical and Applied Mechanics. Elsevier.

[50] Johnnie T. Dennis (2003). The Complete Idiot's Guide to Physics. Alpha Books.

[51] Ştefan Vlăduţescu (2006). Comunicare jurnalistică negativă. Bucureşti: Editura Academiei.

[52] R. Stichweh, Acta Sociologica 43(1) (2000).

[53] Ludwig von Bertalanffy (1962). General Systems Theory: A Critical Review. London.

[54] Paul Watzlawick, Janet Helmick Beavin, Don J. Jackson (1967). Pragmatics of Human Communication. New York: Norton.

[55] Ştefan Vlăduțescu, International Letters of Social and Humanistic Sciences 16 (2014) 86-95.

[56] Jason L. Powell, International Letters of Social and Humanistic Sciences 17(1) (2014) $1-60$.

[57] Aurelia Traistaru, Marioara Avram, International Letters of Social and Humanistic Sciences 13 (2014) 79-88.

[58] Ştefan Vlăduţescu (2010). Formule existenţiale şi adresări literare. Craiova: Editura Sitech.

[59] Jason L. Powell, International Letters of Social and Humanistic Sciences 16(2) (2014) 108-121.

[60] Jason L. Powell, International Letters of Social and Humanistic Sciences 16(2) (2014) 132-143.

[61] Jason L. Powell, International Letters of Social and Humanistic Sciences 16(2) (2014) 177-183. 
[62] Goran Rajović, Jelisavka Bulatović, International Letters of Social and Humanistic Sciences 15(2) (2014) 125-137.

[63] Ioan Constantin Dima, Janusz Grabara, Vladimir Modrak, International Letters of Social and Humanistic Sciences 15(2) (2014) 148-156.

[64] Nirmal Kumar Betchoo, International Letters of Social and Humanistic Sciences 16(1) (2014) 39-48. 